\title{
Association Between the Frequency of Eating Non-home-prepared Meals and Women Infertility in the United States
}

\author{
Sohyae Lee', Jin-young Min ${ }^{2}$, Hye-Jin Kim ', Kyoung-bok Min ${ }^{1}$ \\ ${ }^{1}$ Department of Preventive Medicine, Seoul National University College of Medicine, Seoul, Korea; ${ }^{2}$ Institute of Health and Environment, Seoul \\ National University, Seoul, Korea
}

Objectives: The purpose of this study was to determine whether eating non-home-prepared meals (NHPM), including fast food, readyto-eat foods, and frozen foods, was associated with self-reported infertility in the United States women.

Methods: Data on diet and infertility from women aged 20-49 years who participated in the 2013-2014 and 2015-2016 National Health and Nutrition Examination Surveys were analyzed $(n=2143)$. Dietary information, including the number and types of NHPM consumed, was obtained from a self-reported questionnaire, and infertility status was analyzed using the following question, "Have you ever attempted to become pregnant over a period of at least a year without becoming pregnant?"

Results: The frequency of NHPM consumption was positively associated with self-reported infertility after adjusting for confounding effects (odds ratio [OR], 2.82; $95 \%$ confidence interval [CI], 1.48 to 5.38 of $>1$ vs. 0 NHPM/d). The odds of infertility were $2-3$ times higher in women who consumed fast food than in those who did not consume fast food (OR, 2.73; $95 \% \mathrm{Cl}, 1.15$ to 6.48 of $>1$ vs. 0 times/d). Conclusions: The frequency and types of NHPM may be a factor contributing to infertility. Although our findings require confirmation, they suggest that eating out may be deleterious to women fecundity.

Key words: Reproductive health, Fast foods, Frozen foods, Cross-sectional studies

\section{INTRODUCTION}

Infertility is defined as the absence of a pregnancy despite engaging in unprotected intercourse for 1 year [1]. Infertility is a global public health issue that affects more than 72.4 million couples throughout the world [2]. In the United States, at pres-

Received: August 1, 2019 Accepted: November 10, 2019

Corresponding author: Kyoung-bok Min, MD, PhD

Department of Preventive Medicine, Seoul National University Colleague of Medicine, 103 Daehak-ro, Jongno-gu, Seoul 03080, Korea

E-mail: minkb@snu.ac.kr

This is an Open Access article distributed under the terms of the Creative Commons Attribution Non-Commercial License (https://creativecommons.org/licenses/bync/4.0// which permits unrestricted non-commercial use, distribution, and reproduction in any medium, provided the original work is properly cited. ent, $6.7 \%$ of married women are infertile, $12.1 \%$ experience difficulty getting pregnant or carrying a pregnancy to term regardless of their marital status (impaired fecundity), and 12.0\% (7.3 million) have received help from infertility services [3]. The use of assisted reproductive technologies for reproductive dysfunction in the United States has steadily increased from 60000 cycles in 1995 [4] to 230000 cycles in 2015 [5]; however, the general and total fertility rates and the number of births in the United States were at a record low in 2018 [6-9].

The cause of infertility in specific individuals is often unknown, but possible causes include advanced age, genes, hormonal disorders, obesity, smoking, and alcohol use [10-14]. Diet is a modifiable factor affecting fertility [10], and increasing evidence supports a significant association between diet and reproductive function [13]. Studies have highlighted the beneficial role 
of healthy diets (i.e., diets high in folic acid, long-chain omega 3 fatty acids, soy, vegetables, fruits, whole grains, and seafood) in lowering the risk of women infertility and improving the results of infertility treatment [10].

Eating home-prepared meals is one of the best ways to consume a healthy diet. A high frequency of home-cooked meals has been associated with intake of higher-quality foods and better health outcomes $[15,16]$. A population-based cohort study in the United Kingdom revealed that eating home-prepared meals was associated with a higher intake of fruits and vegetables, greater adherence to Mediterranean and Dietary Approaches to Stop Hypertension diets, higher plasma vitamin C levels, and normal body mass indices (BMI) and percentage body fat ranges [15]. A cohort study in Taiwan reported that elderly individuals who cooked and prepared food at home more frequently ( $>5$ times/wk, compared with never) lived significantly longer [17]. In addition, eating home-cooked meals results in reduced exposure to endocrine-disrupting chemicals (EDCs) in foods [18]. Several studies have revealed that individuals who consume non-home-prepared meals (NHPM) were more likely to be exposed to EDCs (e.g., phthalate and bisphenol A), which are associated with food processing and packaging $[18,19]$. Taken together, eating NHPM may be associated with infertility, as a result of an imbalanced diet with a higher fat composition [20] or through exposure to the higher levels of EDCs used in packaged foods [21]. Nevertheless, the relationship between NHPM and infertility has received limited attention.

In the present study, we aimed to assess whether the frequency of NHPM, including fast food, ready-to-eat foods, and frozen foods, was associated with self-reported infertility in United States women.

\section{METHODS}

\section{Study Population}

Data on diet and infertility were obtained from the 20132014 and 2015-2016 National Health and Nutrition Examination Surveys (NHANES), a nationally representative survey of the non-institutionalized civilian population in the United States (https:// wwwn.cdc.gov/nchs/nhanes/). Overall 10251 women were included from both cycles and 3723 responded to the question regarding their lifetime history of infertility. The analysis was restricted to sexually experienced non-pregnant women $(n=3487)$. Women with a history of hysterecto- my and/or bilateral oophorectomy ( $\mathrm{n}=397)$, women 50 years and older ( $n=567)$, and women experiencing menopause $(n=59)$ were excluded. Among these subjects, 2461 women responded to the question regarding the frequency of NHPM and 2143 women had data for all covariate variables (Figure 1).

\section{Assessment of Non-home-prepared Meals}

Information on the number and types of NHPM that participants consumed was derived from the self-reported diet behavior and nutrition questionnaire (https://wwwn.cdc.gov/ nchs/nhanes/). To assess the frequency of NHPM consumption, the participants were asked the following question: "During the past 7 days, how many meals were prepared away from home in places such as restaurants, fast food places, food stands, grocery stores, or from vending machines?" Herein, meals provided as part of school lunches, school breakfasts, or community programs were not included. Three additional questions addressing the type of NHPM were included, as follows: (1) "How many of those meals did you get from a fast-food or pizza place?" (2) "Some grocery stores sell'ready to eat' foods such as salads, soups, chicken, sandwiches and cooked vegetables in their salad bars and deli counters. During the past 30 days, how often did you eat 'ready to eat' foods from the grocery store? (not including sliced meat or cheese you buy for sandwiches and frozen or canned foods)" and (3) "During the past 30 days, how often did you eat frozen meals or frozen pizzas?" For the statistical analysis, the frequency of NHPM (per day) was divided into 3 categories: none, less than or equal to once per day, and more than once per day.

\section{Self-reported Infertility}

Infertility is defined as the absence of pregnancy despite engaging in unprotected intercourse for 1 year [1]. The presence of infertility was assessed using a self-reported questionnaire. Women aged 20 years and older were considered to have experienced infertility based on their answer to the following question: "Have you ever attempted to become pregnant over a period of at least a year without becoming pregnant?" Women replying "yes" were identified as infertile, and women replying "no" were identified as fertile.

\section{Other Variables of Interest}

Variables of interest were obtained from the interview data of the 2013-2016 NHANES and included age (20-29, 30-39, or 40-49), ethnicity (non-Hispanic white, non-Hispanic black, His- 


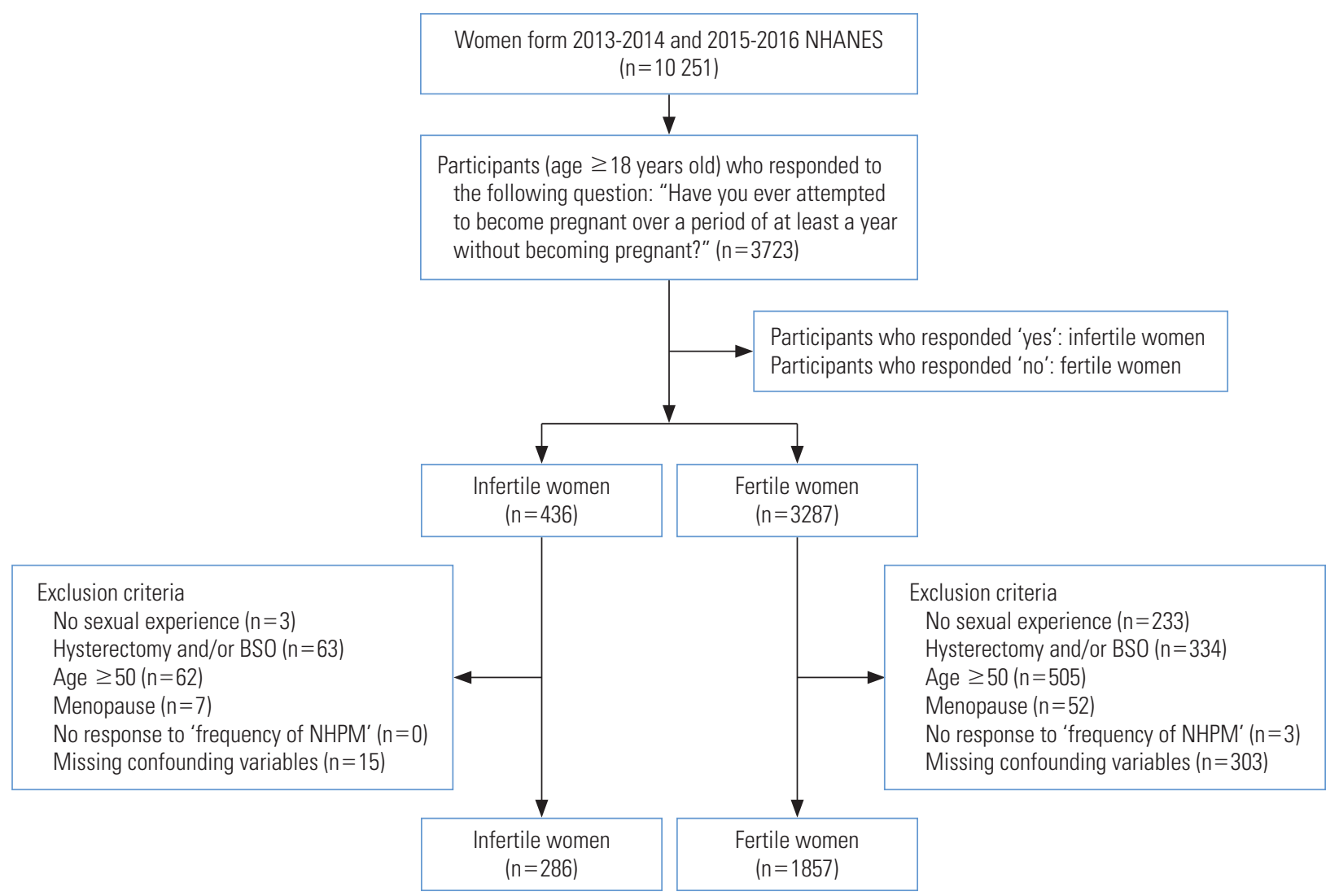

Figure 1. Flow chart of study population selection. NHNANES, National Health and Nutrition Examination Survey; BSO, bilateral salpingo-oophorectomy; NHPM, non-home-prepared meals.

panic, or others), annual family income (less than US\$20 000 or US\$20 000 or more), education (less than high school, high school graduate, or more than high school), occupation (yes or no), marital status (married, never married, or widowed, divorced, separated, living with partner), total number of people in the household (1, 2, 3, 4, 5, 6, or 7 and above), smoking status (never, ex-smoker, or current smoker), alcohol consumption (yes or no), physical activity (yes or no), BMI (underweight [ $\left.<18.5 \mathrm{~kg} / \mathrm{m}^{2}\right]$, normal weight [18.5-24.9 $\left.\mathrm{kg} / \mathrm{m}^{2}\right]$, overweight $\left[25.0-29.9 \mathrm{~kg} / \mathrm{m}^{2}\right]$, or obesity [ $\left.\left.\geq 30.0 \mathrm{~kg} / \mathrm{m}^{2}\right]\right)$, and depression (yes or no). Alcohol consumption [22,23] and physical activity $[24,25]$ were classified according to previous studies conducted using the NHANES. Alcohol consumption was assessed using the following question: "In any one year, have you had at least 12 drinks of any type of alcoholic beverage?" Physical activity was assessed using the following question: "In a typical week do you do any moderate-intensity sports, fitness, or recreational activities that cause a small increase in breathing or heart rate such as brisk walking, bicycling, swimming, or volleyball for at least 10 minutes continuously?"

\section{Statistical Analysis}

Statistical differences in demographics and health behaviors between the 2 groups (fertile vs. infertile) were evaluated using the chi-square test. To evaluate the association between NHPM and infertility, logistic regression analyses were performed using the PROC SURVEYLOGISTIC procedure. We calculated the odds ratio (OR) of the correspondence between infertility and the frequency of NHPM or consumption of different types of NHPM with its $95 \%$ confidence interval (Cl) in comparison with women who consumed only home-prepared meals (reference group). The regression models were adjusted for age, ethnicity, annual family income, education, occupation, marital status, total number of people in the household, smoking history, alcohol consumption, physical activity, BMI, and depression.

According to the NHANES analytic and reporting guidelines, all analyses applied weighted estimates of the population parameters to account for the complex sampling design. The SAS version 9.4 (SAS Institute Inc., Cary, NC, USA) was used. 


\section{Ethics Statement}

The NHANES constitutes a publicly opened national statistical database without personally identifiable information, we performed a secondary analysis of the data without institutional review board approval.

\section{RESULTS}

\section{Characteristics of the Study Participants}

The socio-demographic characteristics of the study participants are shown in Table 1. The overall prevalence of infertility in this sample was $13.4 \%$ (286 cases). Participants with infertility were more likely to be older, married, and obese. There were no statistically significant differences in ethnicity, annual family income, education, occupation, total number of people in the household, smoking history, alcohol consumption, physical activity, or depression between the infertile and fertile women.

\section{Prevalence of Infertility According to Type of Diet}

Figure 2 shows the prevalence of infertility according to the number and types of NHPM consumed. The prevalence of infertility showed a statistically significant increase with the frequency of NHPM consumption, as $19.8 \%$ of those who ate more than 1 NHPM per day reported infertility, in contrast to only $13.6 \%$ and $8.6 \%$ of those who ate $\leq 1$ or no NHPM/d, respectively. Among the types of NHPM, the frequency of meals from fast food/pizza places showed a statistically significant association with the prevalence of infertility. Although the prevalence of infertility also increased with the frequency of consuming

Table 1. Characteristics of the study population

\begin{tabular}{lccc}
\hline Characteristics & Infertile $^{\mathbf{1}}$ & Fertile $^{\mathbf{1}}$ & p-value \\
\hline Total & $286(13.4)$ & $1857(86.7)$ & \\
Age (y) & & & $<0.001$ \\
$20-29$ & $65(8.8)$ & $677(91.2)$ & \\
$30-39$ & $103(14.0)$ & $634(86.0)$ & \\
$40-49$ & $118(17.8)$ & $546(82.2)$ & \\
Ethnicity & & & 0.531 \\
Non-Hispanic white & $111(14.6)$ & $649(85.4)$ & \\
Non-Hispanic black & $63(13.6)$ & $399(86.4)$ & \\
Hispanic & $69(12.1)$ & $503(87.9)$ & \\
Others & $43(12.3)$ & $306(87.7)$ & \\
Annual family income (US\$) & & & 0.968 \\
$<20000$ & $57(13.3)$ & $372(86.7)$ & \\
$\geq 20000$ & $229(13.4)$ & $1485(86.6)$ & \\
\hline & & (Continued to the next)
\end{tabular}

Table 1. Continued

\begin{tabular}{|c|c|c|c|}
\hline Characteristics & Infertile $^{1}$ & Fertile $^{1}$ & $p$-value \\
\hline Education & & & 0.519 \\
\hline Less than high school & $37(11.4)$ & $288(88.6)$ & \\
\hline High school graduate & $55(13.4)$ & $355(86.6)$ & \\
\hline More than high school & $194(13.8)$ & $1214(86.2)$ & \\
\hline Occupation & & & 0.441 \\
\hline Yes & $193(13.0)$ & $1295(87.0)$ & \\
\hline No & $93(14.2)$ & $562(85.8)$ & \\
\hline Marital status & & & $<0.001$ \\
\hline Married & $178(17.8)$ & $821(82.2)$ & \\
\hline Never married & $43(7.2)$ & $557(92.8)$ & \\
\hline Widowed/divorced/separated & $65(12.0)$ & $479(88.1)$ & \\
\hline Total no. of people in the household & & & 0.026 \\
\hline 1 & $13(13.0)$ & $87(87.0)$ & \\
\hline 2 & $49(12.1)$ & $357(87.9)$ & \\
\hline 3 & $80(16.4)$ & $408(83.6)$ & \\
\hline 4 & $56(12.2)$ & 402 (87.8) & \\
\hline 5 & $58(16.1)$ & $303(83.9)$ & \\
\hline 6 & $12(6.7)$ & $167(93.3)$ & \\
\hline$\geq 7$ & $18(11.9)$ & $133(88.1)$ & \\
\hline Smoking history & & & 0.420 \\
\hline Never smoked & $196(13.0)$ & $1307(87.0)$ & \\
\hline Ex-smoker & $40(16.0)$ & $210(84.0)$ & \\
\hline Current smoker & $50(12.8)$ & $340(87.2)$ & \\
\hline Alcohol consumption ${ }^{2}$ & & & 0.269 \\
\hline Yes & $201(13.9)$ & $1244(86.1)$ & \\
\hline No & $85(12.2)$ & 613 (87.8) & \\
\hline Physical activity ${ }^{3}$ & & & 0.582 \\
\hline Yes & $129(12.9)$ & $870(87.1)$ & \\
\hline No & $157(13.7)$ & $987(86.3)$ & \\
\hline Body mass index $\left(\mathrm{kg} / \mathrm{m}^{2}\right)$ & & & $<0.001$ \\
\hline Underweight (<18.5) & $3(7.5)$ & 37 (92.5) & \\
\hline Normal weight (18.5-24.9) & $83(11.7)$ & $625(88.3)$ & \\
\hline Overweight (25.0-29.9) & $51(9.5)$ & $487(90.5)$ & \\
\hline Obesity ( $\geq 30.0$ ) & $149(17.4)$ & 708 (82.6) & \\
\hline Depression ${ }^{4}$ & & & 0.467 \\
\hline Yes & $205(13.0)$ & $1369(87.0)$ & \\
\hline No & $81(14.2)$ & $488(85.8)$ & \\
\hline
\end{tabular}

Values are presented as number (\%).

'Infertile if subject responded 'yes,' 'Fertile' if subject responded 'no' to the following question: "Have you ever attempted to become pregnant over a period of at least a year without becoming pregnant?"

${ }^{2}$ Response to the question: "In any one year, have you had at least 12 drinks of any type of alcoholic beverage?"

${ }^{3}$ Response to the question: "In a typical week do you do any moderateintensity sports, fitness, or recreational activities that cause a small increase in breathing or heart rate such as brisk walking, bicycling, swimming, or volleyball for at least 10 minutes continuously?"

${ }^{4}$ Response to the question: "Over the last 2 weeks, have you been bothered by the following problems: feeling down, depressed, or hopeless?" 


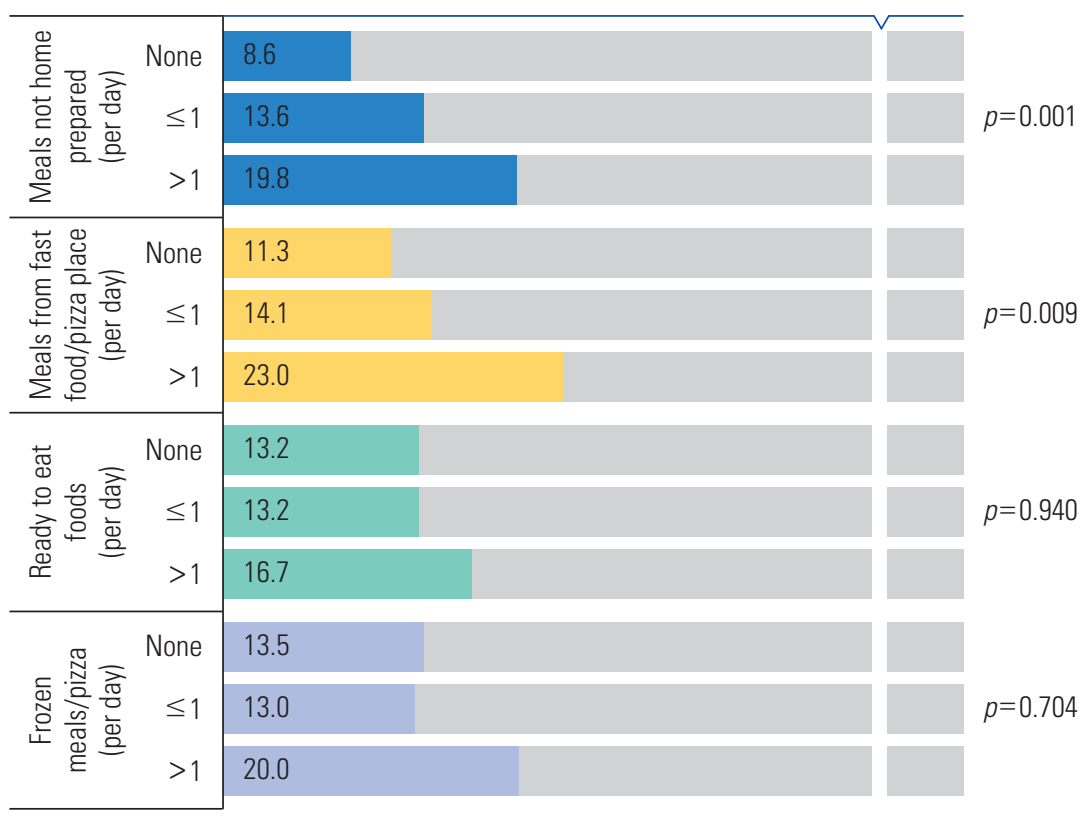

Figure 2. Prevalence (\%) of infertility according to the number and types of non-home-prepared meals.

Table 2. Odds ratio (95\% confidence interval) of infertility associated with non-home-prepared meals (per day)

\begin{tabular}{|c|c|c|c|c|c|}
\hline \multirow{2}{*}{ Variables } & \multirow{2}{*}{ Total, n (\%) } & \multicolumn{2}{|c|}{ No. of subjects } & \multicolumn{2}{|c|}{ Odds of being infertile } \\
\hline & & Infertile & Fertile & Age-adjusted model ${ }^{1}$ & All-adjusted model ${ }^{2}$ \\
\hline \multicolumn{6}{|l|}{ Non-home-prepared meals } \\
\hline None & $338(15.8)$ & 29 & 309 & 1.00 (reference) & 1.00 (reference) \\
\hline Less than or equal to once per day & $1608(75.0)$ & 218 & 1390 & $1.41(0.85,2.32)$ & $1.45(0.82,2.58)$ \\
\hline More than once per day & $197(9.2)$ & 39 & 158 & $2.47(1.35,4.52)$ & $2.82(1.48,5.38)$ \\
\hline \multicolumn{6}{|l|}{ Meals from fast food/pizza places } \\
\hline None & $805(37.6)$ & 91 & 714 & 1.00 (reference) & 1.00 (reference) \\
\hline Less than or equal to once per day & $1264(59.0)$ & 178 & 1086 & $1.41(0.98,2.03)$ & $1.37(0.96,1.95)$ \\
\hline More than once per day & $74(3.5)$ & 17 & 57 & $2.66(1.11,6.36)$ & $2.73(1.15,6.48)$ \\
\hline \multicolumn{6}{|l|}{ Ready-to-eat foods } \\
\hline None & $1333(62.6)$ & 176 & 1157 & 1.00 (reference) & 1.00 (reference) \\
\hline Less than or equal to once per day & 786 (36.9) & 104 & 682 & $0.90(0.67,1.22)$ & $0.95(0.69,1.30)$ \\
\hline More than once per day & $12(0.6)$ & 2 & 10 & $0.84(0.10,6.84)$ & $1.06(0.12,9.79)$ \\
\hline \multicolumn{6}{|l|}{ Frozen meals/pizza } \\
\hline None & $1227(57.3)$ & 166 & 1061 & 1.00 (reference) & 1.00 (reference) \\
\hline Less than or equal to once per day & $900(42.0)$ & 117 & 783 & $1.01(0.73,1.39)$ & $0.98(0.70,1.36)$ \\
\hline More than once per day & $15(0.7)$ & 3 & 12 & $1.91(0.42,8.75)$ & $2.12(0.48,9.42)$ \\
\hline
\end{tabular}

${ }^{1}$ Adjusted models are adjusted for age.

${ }^{2}$ Adjusted models are adjusted for age, ethnicity, annual family income, education, occupation, marital status, total number of people in the household, smoking history, alcohol consumption, physical activity, body mass index, and depression.

ready-to-eat foods and frozen meals, neither of those relationships was statistically significant. Furthermore, the prevalence of infertility according to the frequency of frozen meals showed a drop in prevalence among those who ate $\leq 1$ frozen meal per day.

\section{Diet and Infertility}

Table 2 presents the associations between NHPM, meals from fast food/pizza places, ready-to-eat foods, frozen meals/pizza, and the odds of being infertile. After adjusting for age, ethnicity, annual family income, education, occupation, marital status, 
total number of people in the household, smoking history, alcohol consumption, physical activity, BMl, and depression, we found that higher frequencies of NHPM and meals from fast food/pizza places were significantly associated with infertility; however, no statistically significant association was observed between ready-to-eat foods or frozen foods and infertility. Compared to women consuming no NHPM, the all-adjusted OR $(95 \% \mathrm{Cl})$ of infertility was $1.45(95 \% \mathrm{Cl}, 0.82$ to 2.58$)$ for intake of $\leq 1$ time/d, and $2.82(95 \% \mathrm{Cl}, 1.48$ to 5.38$)$ for intake of $>1$ time/d. In addition, women consuming fast food/pizza $>1$ time/d were 2-3 times more likely to be infertile than women consuming no fast food/pizza (all-adjusted OR, 2.73; 95\% $\mathrm{Cl}, 1.15$ to 6.48 ). The frequency of consuming ready-to-eat foods and frozen meals/pizza showed a dose-response relationship with infertility; however, such associations were not significant (all-adjusted OR for ready-to-eat foods, $0.95 ; 95 \% \mathrm{Cl}, 0.69$ to 1.30 of $\leq 1$ vs. 0 times/d and all-adjusted OR, 1.06; $95 \% \mathrm{Cl}, 0.12$ to 9.79 of $>1$ vs. 0 times/d; all-adjusted OR for frozen meals/ pizza, $0.98 ; 95 \% \mathrm{Cl}, 0.70$ to 1.36 of $\leq 1$ vs. 0 times/d and all-adjusted $\mathrm{OR}, 2.12 ; 95 \% \mathrm{Cl}, 0.48$ to 9.42 of $>1$ vs. 0 times/d).

\section{DISCUSSION}

In a cross-sectional study of United States women sampled from the 2013-2014 and 2015-2016 NHANES, the frequency of NHPM consumption was positively associated with self-reported infertility. Among women, the odds of infertility were approximately 2-3 times higher in women who consumed fast food than in those who did not consume fast food. Our study results suggest that NHPM may be a factor explaining health disparities in infertility.

The odds of infertility in women who consumed ready-to-eat foods and frozen meals/pizza increased with greater frequencies of intake; however, the all-adjusted ORs were statistically insignificant. This may have been due to the small sample size of women consuming such foods ( $n=12$ for women consuming ready-to-eat foods $>1$ time/d, $\mathrm{n}=15$ for women consuming frozen meals/pizza $>1$ time/d), and further studies with larger sample sizes are recommended to clarify such relationships.

Although a healthy diet is a recognized modifiable factor that increases the likelihood of a successful pregnancy [10], few studies have investigated the relationship between NHPM (as an indicator of healthy diet) and infertility. To the best of our knowledge, this study is the first to report that the frequency of NHPM consumption was associated with a higher likelihood of infer- tility. Previous research has investigated the relationship between pre-pregnancy nutrition and time to pregnancy and infertility [26]. A study by Grieger et al. [26], including a total of 5628 nulliparous pregnant women, retrospectively collected data on self-reported time to pregnancy and preconception dietary intake, in terms of the frequency of fast food, fruit, vegetable, and fish intake 1 month prior to conception. Higher intake of fast food and lower intake of fruit (which is associated with NHPM [15]) were associated with modestly longer times to pregnancy and infertility [26]. The results shed light on the importance of eating a good-quality diet, specifically including regular intake of fruits, and minimizing fast food consumption for improving fecundity.

A possible explanation for the observed association may be in conformance with previously suggested hypotheses [26]. Of note, NHPM contain higher amounts of saturated fats, which possibly contribute to infertility and pregnancy loss [20]. An analysis of follicular fluid samples obtained during oocyte retrieval from 100 women undergoing ovarian hyperstimulation as part of in vitro fertilization or intracytoplasmic sperm injection due to infertility in Iran revealed that higher concentrations of saturated fatty acids were associated with lower numbers of mature oocytes [27]. The composition of follicular fluid, which plays an important role in oocyte development and women fertility [28], reflected that of the diet $[27,29]$. Animal experimentation has also supported the association between fat consumption and infertility. A study investigating the relationship between a high-fat diet and lipotoxicity of granulosa cells and the cumulus-oocyte complex in mice showed that the oocytes of mice fed a high-fat diet had higher lipid content, stress markers, and rates of apoptosis than those of mice fed a controlled diet. In addition to oocyte apoptosis rates, mice fed a high-fat diet exhibited increased anovulation and decreased in vivo fertilization rates [30]. In addition, NHPM such as fast foods contain greater amounts of sodium than home-prepared meals [31], and a study in mice revealed that high salt consumption interfered with ovarian folliculogenesis [32]. Another possible explanation is that consuming NHPM increases one's exposure to EDCs, which are commonly used to manufacture plastic food packaging [19]. EDCs interfere with aspects of hormonal action, resulting in impaired women fecundity [21]. Previous studies have revealed a positive doseresponse relationship between fast food intake and exposure to phthalates [18], and although the results are inconsistent, studies have revealed a relationship between increased 
phthalate concentrations and decreased fecundity [33]. Taken together, we speculate that eating NHPM, especially fast foods, may contribute to infertility through increased fat or sodium consumption or exposure to EDCs.

The current study used a large sample to establish an association between NHPM consumption and infertility. Nevertheless, this study has several limitations. First, due to its crosssectional design, we cannot confirm any temporal or causal relationship. Secondly, infertility as a self-reported measure has limitations. Although self-reported difficulty conceiving is a useful measure of infertility, there are various definitions of infertility (e.g., calendar-derived measurements of time spent trying to conceive or medical records) [34], and studies examining the effects of variations in definitions of infertility concluded that the definition of infertility has an impact on measured infertility prevalence [35]. In our study, women who had never tried to conceive in the past may have been automatically included in the 'fertile' group. In order to minimize misclassification between fertile and infertile women, we only included sexually experienced women in our study population. Despite this fact, our classification of infertility may not have been completely accurate, and further replication studies should be conducted, taking various definitions of infertility into consideration. Thirdly, the assessment of dietary intake was based on retrospective recall. Previous studies have also assessed home-prepared meals and fast food intake retrospectively based on single questions, supporting the adequacy of such measures $[26,36,37]$. Nevertheless, recall bias may have been present due to the retrospective nature of the measure. Furthermore, male factor infertility is a relevant factor in as many as $50 \%$ of infertility cases [38]; however, the participants of the infertility questionnaire used in our study were limited to women. Thus, we were able neither to assess male factor infertility nor to consider it as a confounding variable. Lastly, although the confounding variables were considered based on the prior literature $[26,39,40]$, not all possible confounding variables may have been controlled for. Some studies have also included parity [39], self-reported polycystic ovarian syndrome, and previous miscarriages [26] as confounding variables. Thus, we cannot exclude the possibility of residual confounding.

In conclusion, we found a significant association between the frequency of NHPM consumption and infertility in a representative sample of United States adults. Although our findings require confirmation, they suggest that eating out may be deleterious to women fecundity.

\section{CONFLICT OF INTEREST}

The authors have no conflicts of interest associated with the material presented in this paper.

\section{FUNDING}

This work was supported by the Basic Science Research Program through the National Research Foundation of Korea (NRF), funded by the Ministry of Education, Science and Technology (grant No. 2019R1A2C1004966).

This work was supported by the Education and Research Encouragement Fund of Seoul National University Hospital.

\section{ACKNOWLEDGEMENTS}

None.

\section{AUTHOR CONTRIBUTIONS}

Conceptualization: SL, KBM. Data curation: SL, HJK, KBM. Formal analysis: SL, HJK. Funding acquisition: KBM. Methodology: SL, JYM, KBM. Writing - original draft: SL, JYM. Writing review \& editing: HJK, KBM.

\section{ORCID}

Sohyae Lee https://orcid.org/0000-0002-8628-028X

Jin-young Min https://orcid.org/0000-0002-6578-7348

Hye-Jin Kim https://orcid.org/0000-0002-9377-7585

Kyoung-bok Min https://orcid.org/0000-0001-9576-0093

\section{REFERENCES}

1. Practice Committee of the American Society for Reproductive Medicine. Diagnostic evaluation of the infertile female: a committee opinion. Fertil Steril 2015;103(6):e44-e50.

2. Boivin J, Bunting L, Collins JA, Nygren KG. International estimates of infertility prevalence and treatment-seeking: potential need and demand for infertility medical care. Hum Reprod 2007;22(6):1506-1512.

3. Centers for Disease Control and Prevention. National survey of family growth [cited 2019 Jul 19]. Available from: https:// www.cdc.gov/nchs/nsfg/key_statistics/i.htm\#infertility.

4. Society for Assisted Reproductive Technology, American Soci- 
ety for Reproductive Medicine. Assisted reproductive technology in the United States and Canada: 1995 results generated from the American Society for Reproductive Medicine/Society for Assisted Reproductive Technology Registry. Fertil Steril 1998;69(3):389-398.

5. Centers for Disease Control and Prevention. Archived ART reports and spreadsheets [cited 2019 Aug 1]. Available from: https://www.cdc.gov/art/reports/archive.html.

6. Brady E. Hamilton BE, Martin JA, Osterman MJ, Rossen LM. Birth: provisional data for 2018; 2019 [cited 2019 Jul 19]. Available from: https://www.cdc.gov/nchs/data/vsrr/vsrr-007-508. pdf.

7. Martin JA, Hamilton BE, Osterman MJ, Driscoll AK, Mathews TJ. Births: final data for 2015. Natl Vital Stat Rep 2017;66(1):1.

8. Martin JA, Hamilton BE, Osterman MJK, Driscoll AK, Drake P. Births: final data for 2017. Natl Vital Stat Rep 2018;67(8):1-50.

9. National Center for Health Statistics. Vital statistics of the United States; 2003 [cited 2019 Jul 19]. Available from: https://www. cdc.gov/nchs/data/TechApp03_1-09.pdf.

10. Gaskins AJ, Chavarro JE. Diet and fertility: a review. Am J Obstet Gynecol 2018;218(4):379-389.

11. Harlev A, Agarwal A, Gunes SO, Shetty A, du Plessis SS. Smoking and male infertility: an evidence-based review. World J Mens Health 2015;33(3):143-160.

12. Hassan MA, Killick SR. Negative lifestyle is associated with a significant reduction in fecundity. Fertil Steril 2004;81(2):384392.

13. Rossi BV, Bressler LH, Correia KF, Lipskind S, Hornstein MD, Missmer SA. Lifestyle and in vitro fertilization: what do patients believe? Fertil Res Pract 2016;2:11.

14. Sim KA, Partridge SR, Sainsbury A. Does weight loss in overweight or obese women improve fertility treatment outcomes? A systematic review. Obes Rev 2014;15(10):839-850.

15. Mills S, Brown H, Wrieden W, White M, Adams J. Frequency of eating home cooked meals and potential benefits for diet and health: cross-sectional analysis of a population-based cohort study. Int J Behav Nutr Phys Act 2017;14(1):109.

16. Tiwari A, Aggarwal A, Tang W, Drewnowski A. Cooking at home: a strategy to comply with US dietary guidelines at no extra cost. Am J Prev Med 2017;52(5):616-624.

17. Chen RC, Lee MS, Chang YH, Wahlqvist ML. Cooking frequency may enhance survival in Taiwanese elderly. Public Health Nutr 2012;15(7):1142-149.

18. Zota AR, Phillips CA, Mitro SD. Recent fast food consumption and bisphenol $A$ and phthalates exposures among the U.S. population in NHANES, 2003-2010. Environ Health Perspect 2016;124(10):1521-1528.

19. Varshavsky JR, Morello-Frosch R, Woodruff TJ, Zota AR. Dietary sources of cumulative phthalates exposure among the U.S. general population in NHANES 2005-2014. Environ Int 2018; 115:417-429.

20. Moshfegh A, Garceau A, Clemens J. Eating behaviors and dietary intakes of older adults: what we eat in America, NHANES 2015-2016 (FS02-07-19). Curr Dev Nutr 2019;3(Suppl ):nzz051. FS02-07-19.

21. Mínguez-Alarcón L, Gaskins AJ. Female exposure to endocrine disrupting chemicals and fecundity: a review. Curr Opin Obstet Gynecol 2017;29(4):202-211.

22. Min JY, Cho JS, Lee KJ, Park JB, Park SG, Kim JY, et al. Potential role for organochlorine pesticides in the prevalence of peripheral arterial diseases in obese persons: results from the National Health and Nutrition Examination Survey 1999-2004. Atherosclerosis 2011;218(1):200-206.

23. Min JY, Min KB. Insulin resistance and the increased risk for smell dysfunction in US adults. Laryngoscope 2018;128(9): 1992-1996.

24. Min JY, Lee KJ, Park JB, Min KB. Perfluorooctanoic acid exposure is associated with elevated homocysteine and hypertension in US adults. Occup Environ Med 2012;69(9):658-662.

25. Min KB, Min JY. Urinary phthalate metabolites and the risk of low bone mineral density and osteoporosis in older women. J Clin Endocrinol Metab 2014;99(10):E1997-E2003.

26. Grieger JA, Grzeskowiak LE, Bianco-Miotto T, Jankovic-Karasoulos T, Moran LJ, Wilson RL, et al. Pre-pregnancy fast food and fruit intake is associated with time to pregnancy. Hum Reprod 2018;33(6):1063-1070.

27. Shaaker M, Rahimipour A, Nouri M, Khanaki K, Darabi M, Farzadi $L$, et al. Fatty acid composition of human follicular fluid phospholipids and fertilization rate in assisted reproductive techniques. Iran Biomed J 2012;16(3):162-168.

28. Revelli A, Delle Piane L, Casano S, Molinari E, Massobrio M, Rinaudo P. Follicular fluid content and oocyte quality: from single biochemical markers to metabolomics. Reprod Biol Endocrinol 2009;7:40.

29. Fouladi-Nashta AA, Wonnacott KE, Gutierrez CG, Gong JG, Sinclair KD, Garnsworthy PC, et al. Oocyte quality in lactating dairy cows fed on high levels of $n-3$ and $n-6$ fatty acids. Reproduction 2009;138(5):771-781.

30. Wu LL, Dunning KR, Yang X, Russell DL, Lane M, Norman RJ, et al. High-fat diet causes lipotoxicity responses in cumulus-oo- 
cyte complexes and decreased fertilization rates. Endocrinology 2010;151(11):5438-5445.

31. Prentice CA, Smith C, McLean RM. Sodium in commonly consumed fast foods in New Zealand: a public health opportunity. Public Health Nutr 2016;19(6):958-966.

32. Wang G, Yeung CK, Zhang JL, Hu XW, Ye YX, Yang YX, et al. High salt intake negatively impacts ovarian follicle development. Ann Anat 2015;200:79-87.

33. Thomsen AM, Riis AH, Olsen J, Jönsson BA, Lindh CH, Hjollund $\mathrm{NH}$, et al. Female exposure to phthalates and time to pregnancy: a first pregnancy planner study. Hum Reprod 2017;32(1): 232-238.

34. Dick ML, Bain CJ, Purdie DM, Siskind V, Molloy D, Green AC. Self-reported difficulty in conceiving as a measure of infertility. Hum Reprod 2003;18(12):2711-2717.

35. Marchbanks PA, Peterson HB, Rubin GL, Wingo PA. Research on infertility: definition makes a difference. Am J Epidemiol
1989;130(2):259-267.

36. Dave JM, An LC, Jeffery RW, Ahluwalia JS. Relationship of attitudes toward fast food and frequency of fast-food intake in adults. Obesity (Silver Spring) 2009;17(6):1164-1170.

37. Tumin R, Anderson SE. Television, home-cooked meals, and family meal frequency: associations with adult obesity. J Acad Nutr Diet 2017;117(6):937-945.

38. Berek JS. Berek \& Novak's gynecology. 16th ed. Philadelphia: Lippincott Williams \& Wilkins; 2019, p. 942-1000.

39. Gudmundsdottir SL, Flanders WD, Augestad LB. Physical activity and fertility in women: the North-Trøndelag Health Study. Hum Reprod 2009;24(12):3196-3204.

40. Rostad B, Schmidt L, Sundby J, Schei B. Infertility experience and health differentials - a population-based comparative study on infertile and non-infertile women (the HUNT Study). Acta Obstet Gynecol Scand 2014;93(8):757-764. 